\title{
PENYU DAN WARGA PULAU SIAU
}

\author{
Evander E. Aiba, Billy Th. Wagey, P. Astony Angmalisang, Anneke V. Lohoo, Deslie R. \\ Kumampung, \& Farnis B. Boneka*
}

Fakultas Perikanan dan IImu kelautan, Universitas Sam Ratulangi, Manado 95115

*Corresponding author: farnisb@gmail.com

\begin{abstract}
The study of the perception residents of the Siau island regarding the existence of sea turtles was carried out from June to December 2018. The survey method and direct observation were applied in data collection. The data collected then were analyzed descriptively. The results showed that $88 \%$ of the residents are well acquainted with the life of sea turtles followed by $80 \%$ of the residents knew of the sea turtles' status as the protected animals through government regulations and international conventions. However, the proportion of residents involved in violating regulations are quite worrying to the survival of sea turtles. For it was found that $29 \%$ of the residents were catching sea turtles, $20 \%$ were selling sea turtle meat and eggs, and $82 \%$ were consuming sea turtle meat and eggs. Thefefore, law enforcement and conservation education are absolutely neccesary for the sustainability of sea turtles in North Sulawesi Indonesia.
\end{abstract}

Keywords: Sea turtle, Siau Island, resident's perception, law enforment. Conservation education

\begin{abstract}
Abstrak
Telaah presepsi warga pulau Siau terhadap keberadaan penyu laut telah dilaksanakan pada JuniDesember 2018. Metode survey dan observasi langsung diaplikasikan dalam pengumpulan data, dan data dianalisa secara deskripsif. Hasil menunjukkan bahwa warga mengenal dengan baik kehidupan penyu $(88 \%)$ dan statusnya sebagai satwa yang dilindungi melalui regulasi pemerintah dan konvensi Internasional (80\%). Namun proporsi warga yang terlibat dalam pelanggaran terhadap peraturan cukup mengkuartirkan akan keberlangsungan hidup penyu, yakni menangkap penyu (29\%), menjual daging dan telur penyu (28\%), mengkonsumsi daging dan telur penyu (82\%). Penegakkan hukum dan edukasi diperlukan demi kelestarian penyu di Sulawesi Utara dan Indonesia pada umumnya.
\end{abstract}

Kata kunci: Penyu laut, Pulau Siau, persepsi warga, penegakan hokum, pendidikan konservasi

\section{PENDAHULUAN}

Dari tujuh jenis penyu di dunia, enam ditemukan di perairan Indonesia (DKP, 2009), empat di antaranya dilaporkan bertelur di wilayah Sulawesi Utara yaitu penyu hijau (Chelonia mydas), penyu sisik (Eretmochelys imbricata), penyu lekang (Lapidochelys olivacea) dan penyu belimbing (Dermochelys coriacea) (Kasenda et al, 2013; Balaira et al, 2017; Langinan et al, 2017; Arunde et al 2018, Boneka FB et al, 2018 ).

Penyu masuk dalam daftar merah IUCN (International Union For Nature and Natural Resources) dan Appendix I CITES (Convention on International Trade in Endangered Species) (DKP, 2009) sebagai biota yang dilindungi. Konservasi penyu diatur melalui konvensi Internasional dan peraturan oleh Pemerintah Indonesia, antara lain dituangkan dalam (a) PP Nomor 7 Tahun 1999 tentang Pengawetan jenisjenis Tumbuhan dan satwa yang dilindungi, dan (b) UU Nomor 5 Tahun 1990 tentang Konservasi Sumber Daya Alam Hayati dan Ekosistemnya. Meski status penyu telah jelas sebagai biota yang dilindungi melalui berbagai regulasi yang telah eksis lebih dari dua dekade bagi Indonesia, namun fakta di Wilayah Sulawesi Utara menunjukkan bahwa biota ini masih terus diburu (Kasenda et al, 2013; Balaira et al, 2017; Langinan et al, 2017; Arunde et al 2018), dan tempat bertelur yang berlokasi lingkungan pesisir terus mengalami perubahan (Ferry dkk, 2013). Dari pertimbangan tersebut, dipandang perlu mengetahui persepsi dan respon warga 
tentang konservasi penyu di wilayah Pulau Siau dan sekitarnya. Diharapkan penelitian ini memberikan motivari bagi warga dan pemerhati konservasi penyu dalam upaya konservasi penyu di Kabupaten Kepulauan Siau Tagulandang Biaro (SITARO) untuk mendukung program pelestarian penyu di Indonesia.

\section{METODE PENELITIAN}

Lokasi \& waktu Penelitian. Survey dilakukan di Pulau Siau dan pulau-pulau kecil sekitar yakni: Gunatin, Pahepa, Kapuliha, Masare, Mahoro dan Laweang; wilayah ini bagian dari Kabupaten Kepulauan Siau Tagulandang Biaro (SITARO). Kabupaten kepulauan ini letak pada $02^{\circ} 45^{\prime} 00^{\prime \prime} \mathrm{LU}$ dan $125^{\circ} 23^{\prime} 59^{\prime \prime} \mathrm{BT}$, luas $\pm 160,02 \mathrm{Km}^{2}$ dengan jumlah penduduk 43.844 (BPS Kab. SITARO, 2018). Pulau Siau berjarak sekitar 85 mil dari Manado, ditempu dengan kapal laut; antar desa atau kecamatan menggunakan kendaraan roda empat (mobil). Survey dilaksanakan sepanjang bulan Juni 2018.

Metode Pengambilan Data. Penelitian ini menggunakan metode survey yakni pengumpulan data primer dalam bentuk pertanyaan kepada responden individu dan observasi langsung ke objek penelitian. Metode survei digunakan sebagai teknik penelitian melalui pengamatan langsung terhadap suatu gejala atau pengumpulan informasi melalui pedoman wawancara (Sutiyono, 2013). Pada penelitian ini wawancara dilakukan dengan menggunakan kuesioner sebagai panduan untuk memperoleh data. Kuesioner yang digunakan adalah kuesioner kombinasi artinya ada pertanyaan yang bersifat terbuka sehingga responden dapat menjawab sesuai dengan pengetahuan mereka mengenai informasi penyu, dan ada pertanyaan yang dijawab dengan memilih. Informasi dari responden dapat dipercaya karena penyu memiliki sifat yang tidak dimiliki oleh hewan lain yakni ia kembali bertelur di tempat yang sama ketika musim memijah tiba. Responden mencakup informan kunci yakni para nelayan, keluarga nelayan, kepala desa dan perangkat desa. Data yang diolah menggunakan metode deskriptif.

\section{HASIL DAN PEMBAHASAN}

Kenal Penyu. Hasil survey mengenai pemahaman masyarakat Pulau Siau dan sekitar tentang penyu ditunjukkan dalam Gambar 1. Sebagian besar responden atau $88 \%$ menyatakan pernah melihat secara langsung penyu di alam atau telah ditangkap nelayan.

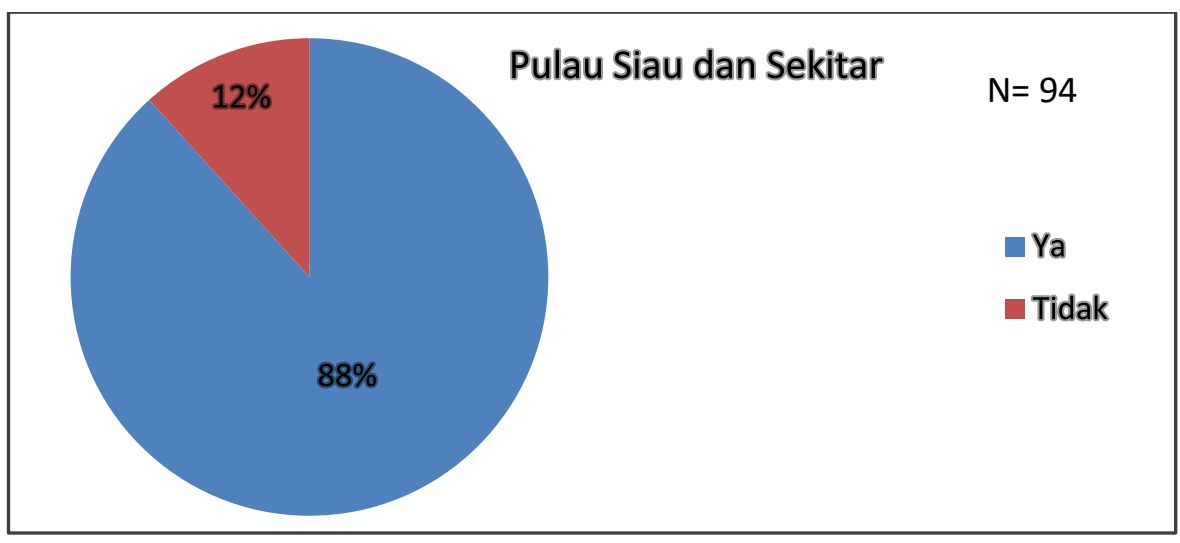

Gambar 1. Respon terhadap pertanyaan "Apakah pernah melihat penyu secara langsung?"

Hasil tersebut di atas mirip dengan yang dilaporkan dari wilayah Talaud oleh Langinan $d k k$ (2017) dan Balaira $d k k$ (2017) dan dari desa-desa pesisir Minahasa Utara oleh Arunde dkk (2018). Warga pulau Siau mampu membedakan jenis-jenis penyu, yaitu penyu hijau dengan nama lokal lenno dan penyu sisik disebut kihha. Kedua jenis penyu ini tergolong umum di wilayah Sulawesi Utara (Kasenda $d k k$, 2013; Langinan $d k k, 2017$; Balaira $d k k, 2017$; Arunde $d k k, 2018)$. Nama lokal 
menjadi indikasi bahwa penyu sudah dikenal lama oleh warga dan jenis yang tergolong umum di daerah tersebut. Dengan demikian, warga kepulauan dan yang bermukim di wilayah pesisir mengenal penyu dengan baik. Kondisi ini memungkinkan warga lokal berpotensi berperan menjaga kelestarian penyu atau pun sebaliknya menjadi sumber ancaman bagi konservasi penyu di wilayahnya.

Selanjutnya, melalui pertanyaan "apakah tahu bahwa Penyu telah dinyatakan sebagai satwa lindung?" Hasil menunjukkan sebagian warga responden (atau $80 \%$ ) telah memiliki pengetahuan bahwa penyu tergolong satwa yang dilindungi melalui regulasi Nasional dan Internasional.
Komoditi ekonomi. Gambar 2 menunjukan proporsi warga sebesar $28 \%$ pernah terlibat dalam jual beli daging atau telur penyu secara terbuka. Pada umumnya penjual adalah keluarga nelayan. Harga daging penyu sekitar Rp 25.000 - 40.000/ kg. Penjualan hanya terbatas di lingkup desa, ditawarkan dari rumah ke rumah penduduk setempat. Proporsi warga yang terlibat dalam penjualan daging penyu di pulau Siau, mirip dengan studi sebelumnya di desa pesisir Minahasa (Kasenda $d k k, 2013$ ) dan Talaud (Langinan $d k k, 2017$; Arunde, $d k k$ 2018). Jual beli daging penyu adalah bentuk pelanggaran hukum. Hal ini kiranya boleh menunjukkan bahwa program sosialisari regulasi konservasi penyu masih lemah dan perlu terus digalakkan.

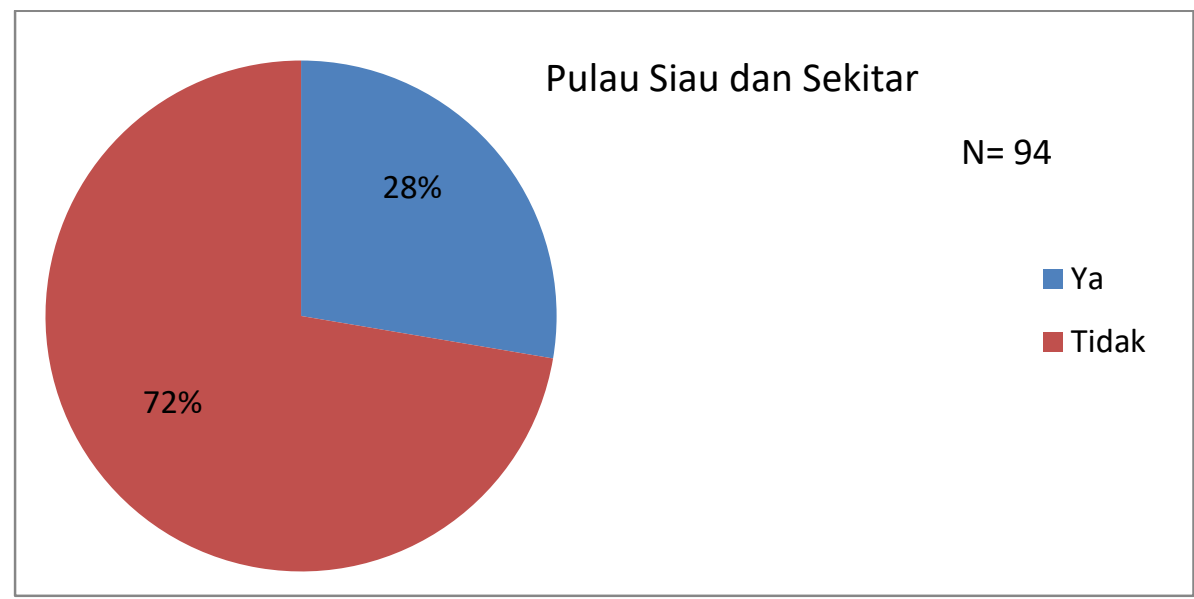

Gambar 2. Respon terhadap pertanyaan "Pernah menjual daging atau telur penyu?

Bahan Makanan. Salah satu faktor pemicu warga masih menangkap penyu adalah kebiasaan mengkonsumsi daging dan telur penyu. Hasil survey menunjukan bahwa sebanyak $82 \%$ responden pernah dan masih mengkonsumsi daging dan telur penyu. Daging penyu biasanya diolah menjadi masakan tradisional yang biasa disebut masakan "tuturuga" yang di dalamnya ada rempah-rempah lokal seperti santan kelapa dan kunyit .Untuk itu penegakan hukum yang konsisten dan nondiskriminatif sangat diperlukan demi menekan pelanggaran hokum khususnya konservasi penyu.
Memburu Penyu. Pada Gambar 3 ditunjukkan proporsi jumlah responden terhadap aktifitas menangkap penyu yakni sekitar 29\% masih melakukannya. Umumnya mereka menangkap penyu di laut, atau di darat pada saat penyu meletakkan telur. Namun terungkap pula melalui wawancara bahwa kebiasaan warga menangkap penyu mulai menurun pada satu decade terakhir, terkait dengan semakin jarang menemui penyu berukuran besar dan muncul rasa takut terlibat dalam masalah hukum. 


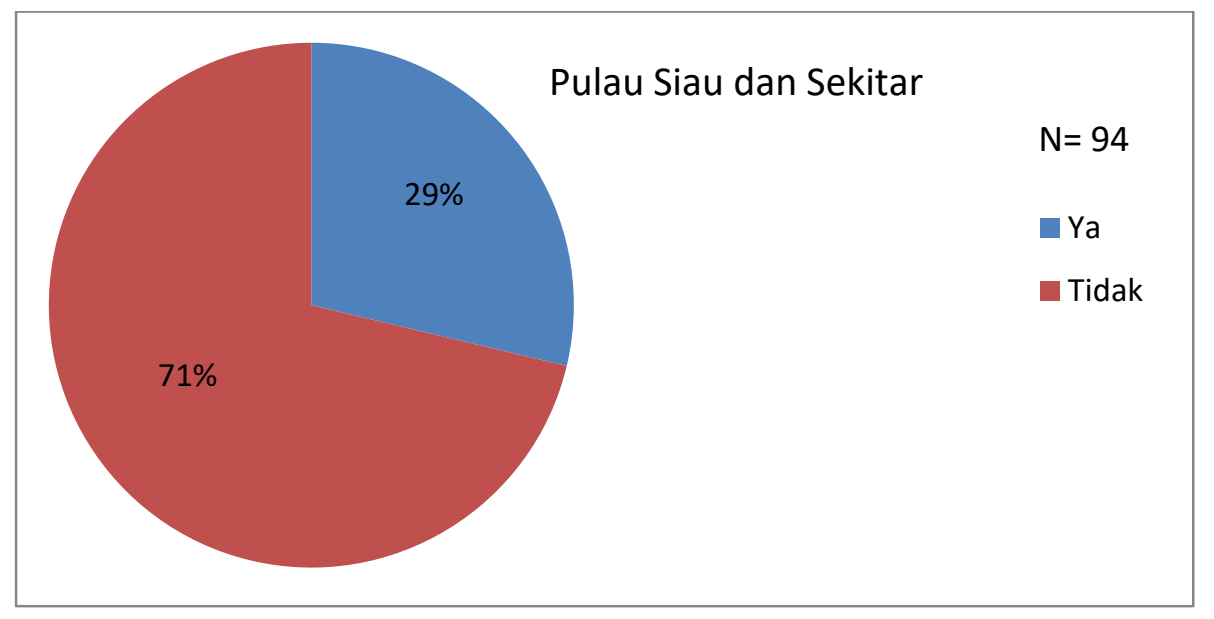

Gambar 3 .Respon masyarakat dengan pertanyaan "Pernah menangkap penyu?"

Alat penangkap penyu. Teridentifikasi terdapat dua jenis alat yang digunakan warga menangkap penyu yaitu tombak dengan nama lokal lote dan panah atau disebut jubi. Lote merupakan alat tradisional khusus penangkap penyu dengan ukuran panjang $90-250 \mathrm{~cm}$, berat 3-5 kg, bagian ujung dinamakan pengait (atau local disebut sangga) yang terbuat dari besi yang sangat tajam dan bagian badan terbuat dari kayu yang dibungkus dengan bahan tima, dilengkapi dengan tali $1,5 \mathrm{~m}$ panjang. Alat jubi pada umumnya digunakan untuk menangkap ikan karang dengan ukuran yang bervariasi; namun digunakan pula untuk memburu penyu. Jubi terbuat dari kayu dengan anak panah terbuat dari besi yang sangat runcing bagian ujung dan memiliki pengait (local: sangga). Panah yang digunakan untuk berburuh penyu biasanya berukuran 22,50 $\mathrm{m}$ dengan panjang tali sekitar $8 \mathrm{~m}$. Cara operasional penggunaan lote dan jubi dijelaskan oleh Balaira dkk (2017).

\section{KESIMPULAN DAN SARAN}

Warga pulau Siau pada umumnya sangat mengenal penyu bahkan mampu membedakannya menurut jenis. Meski telah mengetahui bahwa penyu sebagai satwa lindung, sebagian nelayan pulau Siau masih menangkap penyu dan menggunakannnya sebagai bahan makanan. Budaya menangkap dan mengkonsumsi daging dan telur penyu dapat ditekan melalui proses edukasi disertai dengan penegakkan hokum yang melibatkan berbagai lembaga atau Institusi di wilayah tersebut.

\section{UCAPAN TERIMA KASIH}

Tulisan ini bagian dari Skripsi Mahasiswa Program Sarjana Prodi IImu Kelautan Evander E. Aiba. Kegiatan pengumpulan data lapangan didukung Dana DIPA Unsrat Tahun 2018.

\section{DAFTAR PUSTAKA}

Adnyana, I.B.W. dan C. Hitipeuw. 2009. Panduan Melakukan Pemantauan Populasi Penyu di Pantai Peneluran di Indonesia. WWF for a living planet and Udayana University.

Arunde, P., F.B. Boneka., B.T. Wagey., G. Mamangkey., I. Manembu dan A. Kambey.2018. Konservasi Penyu di Pulau Talise, Gangga dan Bangka Kabupaten Minahasa Utara. Jurnal Budidaya Perairan, 6(2): 61-67.

Balaira, E.N., F.B. Boneka dan B.T. Wagey. 2017. Tempat Bertelur Penyu di Pulau Salibabu Kabupaten Kepulauan Talaud. Jurnal Pesisir dan Laut Tropis, 1(2): 20-25.

Boneka, F.B. 2012. Penyu Laut. Biologi, Konservasi dan Kendala.Bahan Penyuluhan di Kabupaten Kepulauan Sitaro. Laboratorium Biologi Kelautan UNSRAT. 
Boneka, F.B., Wagey, Th.B., Ompi, M. dan Mamangkey, N.G.F. 2018. Inventarisasi Tempat Bertelur Penyu Laut di Wilayah Kepulauan Siau Tagulandang Biaro (SITARO). Laporan Penelitian dibiayai dari DIPAUnsrat KementerianRiset, Teknologi dan PendidikanTinggi Tahun 2018.

BPS (Badan Pusat Statistik) 2018. Kabupaten Kepulauan Siau Tagulandang Biaro Dalam Angka 2019.https://sitarokab.bps.go.id/publika si.html. Dikunjungi September 2019.

DKP (Departemen Kelautan dan Perikanan), 2009. Pedoman Teknis Pengelolaan Konsevasi Penyu. Diterbitkan Oleh Direktorat Konservasi dan Taman Nasional Laut, Direktorat Jenderal Kelautan, Pesisir dan PulauPulau Kecil, Departemen Kelautan dan Perikanan RI.

Dahuri,R.2003. Keanekaragaman Hayati Laut;Aset Pembangunan Berkelanjutan Indonesia,PT.Gramedia Pustaka Umum,Jakarta.

Ferry, A., Syafruddin, S. \& Sarma, S. 2013. Habitat Tempat Bertelur Penyu Hijau (Chelonia mydas) di Kawasan Taman Wisata Alam Sungai Liku Kabupaten Sambas Kalimantan Barat. Universitas Tanjungpura.

Kasenda, P., F.B. Boneka dan B.T. Wagey. 2013. Lokasi Bertelur Penyu di Pantai Timur Kabupaten Minahasa Provinsi Sulawesi Utara. Jurnal Pesisir dan Laut Tropis, 2(1): 58-62.

Langinan, F., F.B. Boneka dan B.T. Wagey. 2017.Aspek Lingkungan Lokasi Bertelur Penyu di Pantai Taturian, Batumbalango Talaud. Jurnal Pesisir dan Laut Tropis, 1(2):26-31.

Mingkid, W.M. 1992. Kemampuan tetas telur penyu Hijau (Chelonia mydas Linnaeus, 1758) dalam wadah alamiah dan modifikasi serta tingkah laku tukik.SKRIPSI Fakultas Perikanan dan IImu Kelautan UNSRAT. Manado.

Nuitja, I.N.S. 1992. Biologi dan Ekologi Pelestarian Penyu Laut. IPB Perss, Bogor.128 hlm.

Pradana, A.F., Said, S., dan Siahaan, S.2013. Habitat Tempat Bertelur Penyu
Hijau (Chelonia mydas) di Kawasan Taman Wisata Alam Sungai Liku Kabupaten Sambas Kalimantan Barat. Fakultas Kehutanan Universitas Tanjung Pura. Jurnal hutan lestari.Vol 1.

Soegijono, R.K. 1993. Wawancara Sebagai Salah Satu Metode. Puslitbang Pelayanan Kesehatan, Badan Litbangkes. 21 hal.

Sugiyono, (2009). Metode Penelitian Kuantitatif Kualitatif dan $R$ \& D. Bandung : Alfabeta.

Sutiyono. 2013. Metode penelitian survey dan korelasional: UPT pendidikan kecamatan gebong Provinsi Jawah tengah.https://sutiyonokudus.files.word pres.com Dikunjungi Agustus 2018.

Tambun, P.C. 2017. Karakteristik Bio-Fisik Habitat Pantai Peneluran Terhadap Tingkat Keberhasilan Penetasan Telur Penyu Hijau (Chelonia mydas) di Pulau Penyu Pesisir Selatan Provinsi Sumatera Barat. SKRIPSI Fakultas Pertanian Universitas Sumatera Utara.http://repositori.usu.ac.id.Dikunju ngi 05 November 2019. 